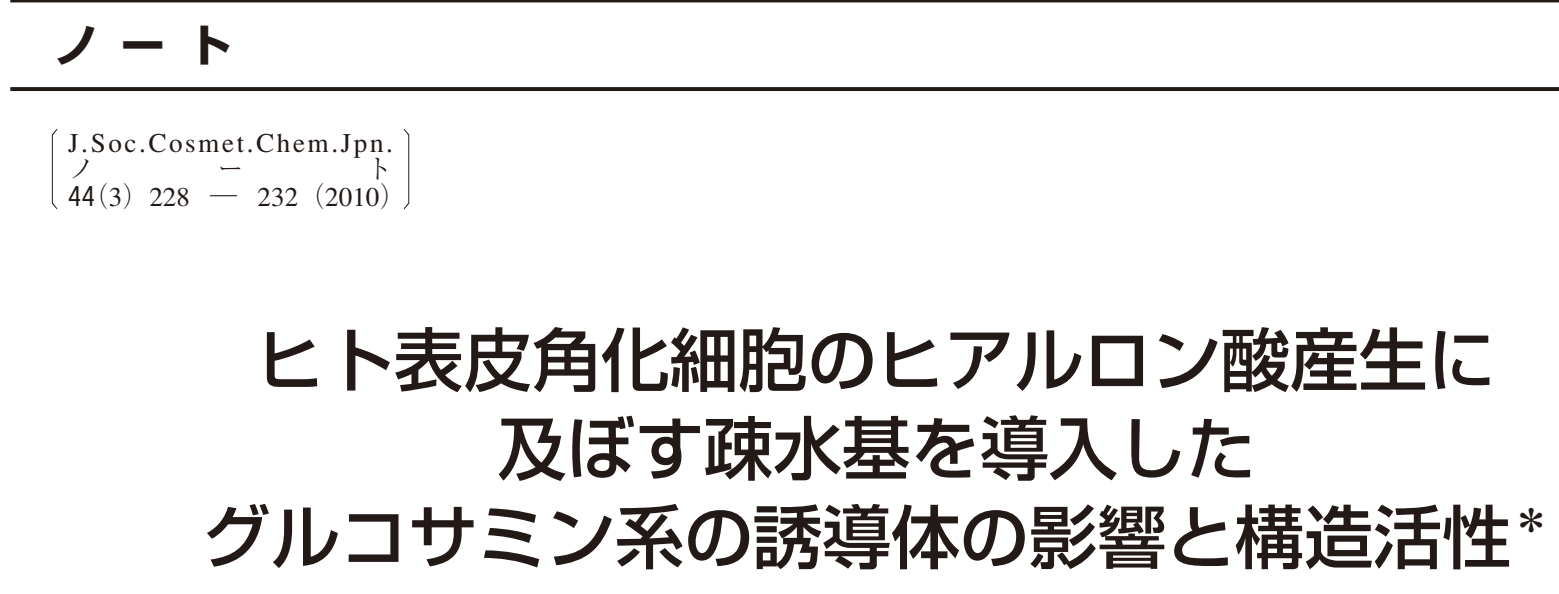

\author{
吉田晋一**, 木村伸一**, 北村圭子***, 情野治良*** \\ （地独）鳥取県産業技術センター 電子 - 有機素材研究所 有機材料科**, \\ ピアス株式会社 中央研究所***
}

\begin{abstract}
D-グルコサミン (GICN) (1)およびN-アセチル-D-グルコサミン (GlcNAc) (2) の新規誘導体を 合成し，表皮角化細胞におけるヒアルロン酸（HA）産生能について検討した。合成した GlcN 誘導 体のうち N-ブチリル-D-グルコサミン(4)に促進作用が観察された。その他の誘導体 3，5，6 は，表 皮角化細胞に対して毒性を示した。側鎖の構造とHA 産生促進効果との関係を調べるために，より 疎水性の高いフッ素やシリカを含むアルコールを結合させた GICNAC 誘導体を合成した（7～15）。 アルキルアルコール, 含フッ素アルコール, 含ケイ素アルコール, 芳香族アルコールに分けて, 結合 アルコールの Log P 值と HA 産生促進能の相関を調べたところ, 同じグル一プ内では疎水性の大き いほうが促進能も高かった。しかしながら,グル一プ間では疎水性に応じた促進効果が観察されず, 他の要因も影響していると推察された。
\end{abstract}

\section{1. 緒言}

ヒアルロン酸（HA）は生態防御に関わる免疫系や電 解質バランスのコントロールに関与するグルコサミノグ リカンの一種であり，真皮のみならず表皮にも存在して いる。皮膚中の HA の減少は肌の老化, 弾力性や柔軟性 の低下の原因にもなることから，表皮の HA 合成力を高 める物質は化粧品素材として有望である。D-グルコサ ミン $(\mathrm{GlcN})$ (1)〔以下, 本文および図中の太字番号は, Fig.-1の構造式番号に対応および $N$-アセチル-D-グル コサミン (GlcNAc)（2）は，ヒアルロン酸を構成する アミノ単糖であり, ほかにもカニやエビ殸, 昆虫類に含 まれるキチン・キトサン, ヘパリンなどのムコ多糖, 細

*2009. 11. 24 受付，2010.4.13 採用

** $7689-1112$ 鳥取市若葉台南 7-1-1 : 7-1-1, Wakabadaiminami, Tottori 689-1112, Japan

*** $\overline{6} 651-2241$ 神戸市西区室谷 1-3-1: 1-3-1, Murotani, Nishi-ku, Kobe 651-2241, Japan
菌多糖などの構成糖である1)。近年, GlcN および GlcNAcの単糖としての生理作用に関する研究が広範に 行われ, GlcN の軟骨細胞の再生効果 ${ }^{2}$ や美肌効果 ${ }^{3)}$, GlcNAc ではHA の合成促進効果 ${ }^{4)}$ や抗炎症作用 ${ }^{5)}$ などが 報告されている。また，アルキル鎖を導入した GlcNAc でHA 産生促進作用が報告されているが6)，その理由に ついては不明な点が多い。

本研究では, 疎水基をもつ GlcN の誘導体が軟骨細胞 でのプロテオグリカンの産生に効果的7であることに 着目し，表皮細胞でも同様な効果が期待される誘導体 （3～6）を新規に合成し（Fig. -1），ヒト表皮角化細胞に 対する毒性試験と HA 産生能について検討を行った。ま た，表皮の HA 産生を高める GlcNAcについては，すで に報告のあるアルキル鎖等を導入した誘導体以外に，新 たにGlcNAcの 1 位にフッ素やケイ素，芳香核を含む側 鎖を導入した誘導体（10１5）を合成し（Fig. - 1)，導 入する疎水基側鎖の構造と HA 産生促進効果について検 討を加えた。 

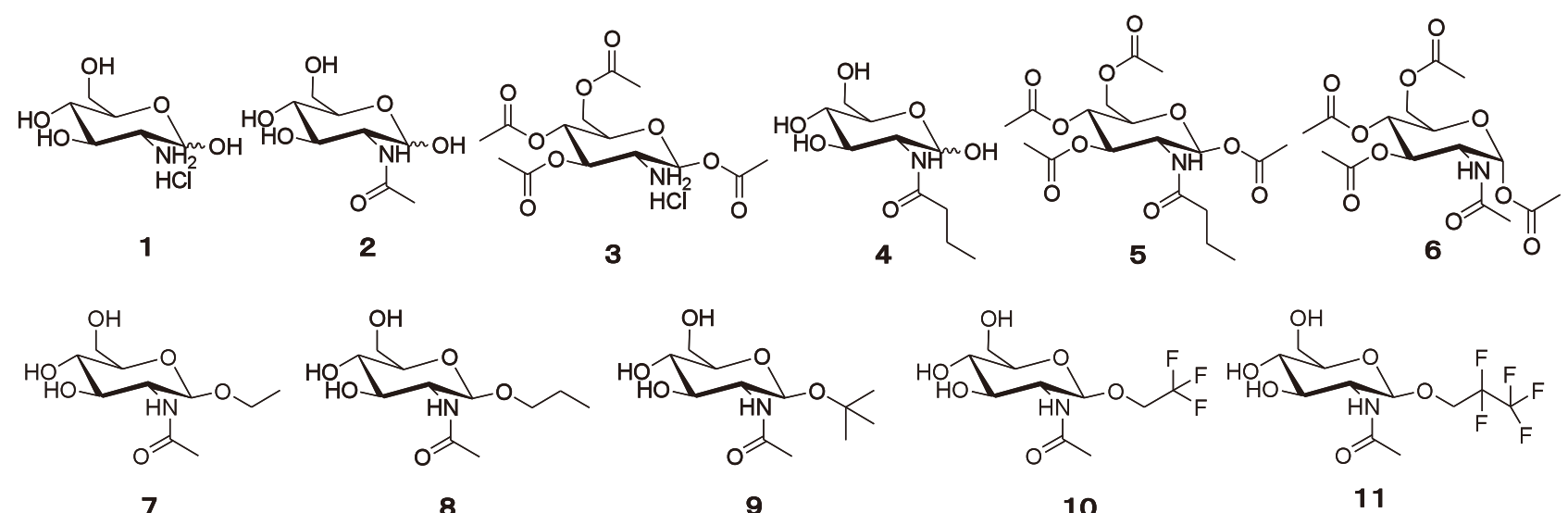

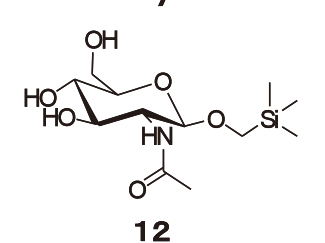

12

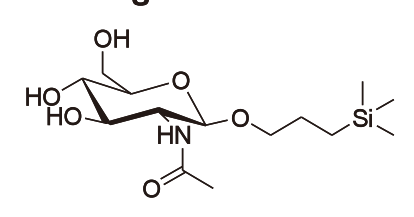

13

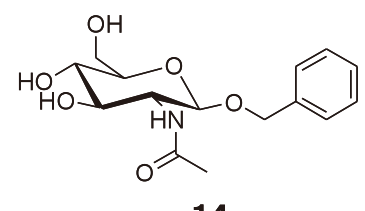

14

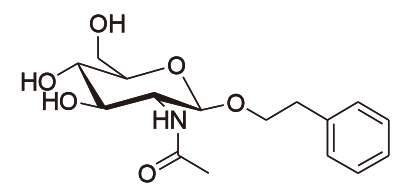

15

Fig. -1 Compounds used in this study.

2. 実

験

\section{1. 化合物の合成}

Fig. -1 に示した化合物のうち, GlcN 誘導体 (3〜6) は, Bergmann $ら^{8)}$ および Inouye $ら^{99}$ の方法を参考に合成し た。GlcNAc 誘導体 (7〜15) は, Nishimura らの方法 ${ }^{10}$ を参考に，対応するアルコール（エタノール， $n$-プロパ ノール，t-ブタノール，2,2,2-トリフルオロエタノール， 2,2,3,3,3-ペンタフルオロ-1-プロパノール，（トリメチル シリル)メタノール，3-(トリメチルシリル)-1-プロパ ノール, ベンジルアルコール，フェネチルアルコール） を用いて合成した。合成物の化学構造は, ${ }^{1} \mathrm{H}-\mathrm{NMR}$, ${ }^{13} \mathrm{C}-\mathrm{NMR}$ およびIRにより確認した。

\section{2. 表皮角化細胞における細胞毒性と HA 産生能の 評価}

ヒト由来表皮角化細胞（KURABO）を 24 well プレー トに $5 \times 10^{4}$ 個ずつ播種し，KG-2 培地（KURABO）で 24 時間培養した。さらに各試験サンプルを含む KG-2 培 地に交換し, $37^{\circ} \mathrm{C}$ で 24 時間培養した。培地に溶解しに くい試験サンプルはDMSO で溶解したのち, DMSOの 濃度が $0.5 \%$ になるように培地に添加した（培地中に含 有される DMSO 濃度を $0.5 \%$ に調整)。2 4 時間培養後の 細胞生存率を Alamar-blue（BIOSOURCE）を用いて測定 した。培養上清を採取し, 上清中の HA 量を ELISA キッ ト (Hyaluronan Assay Kit, 生化学バイオビジネス社製) により測定した。HA 産生促進作用は試験サンプルを含 有しないコントロールを100とした試験サンプルの index（\%）により評価した。

\section{3. 結果および考察}

\section{1. ヒト表皮角化細胞を用いた GlcN 誘導体 (3〜6) の評価}

GlcN（1）は, 軟骨細胞の再生に効果的2)とされるが, 最近の研究で GlcN は滑膜細胞において HA の合成を促 進することが報告されている3), 11)。さらに, GlcNの $N$ 位にブチル基を導入した誘導体（N-ブチリル-D-グルコ サミン（GlcNBu）（4））を添加すると, $\mathrm{GlcN}$ そのもの を添加した場合に比べて，軟骨細胞によるマトリックス 遺伝子発現が大きくなることが報告されており，作用機 序として, 疎水性の付与による細胞膜への浸透性の促進 効果が指摘されている7)。しかしながら，ヒト表皮細胞 に対する効果は，検証されていない。われわれは，まず GlcN（1）に，種々の疎水基を導入することにより，細 胞膜への浸透作用による HA の合成促進作用の向上が期 待される誘導体（4 種）を合成し，これらの誘導体のヒ 卜表皮細胞における細胞毒性や HA の産生促進作用を評 価した。

Fig.-2A に細胞生存率について示す。比較のために, GlcN（1）およびGlcNAc（2）のデー夕も示す。GlcNBu （4）については，生存率の低下は観察されなかったが, 他の GlcN 誘導体 3，5，6では $0.25 \%$ 濃度でも生存率は $10 \%$ 未満であり, 強い細胞毒性を示した。遊離のアミノ 基を有する誘導体 3 は, 細胞膜に対して吸着破壊を示す カチオン界面活性剤 ${ }^{12)}$ として作用することにより, 細胞 毒性を示していると推察される。誘導体 5 と 6 の細胞毒 性についても, 原因は定かでないが, 水酸基にアセチル 


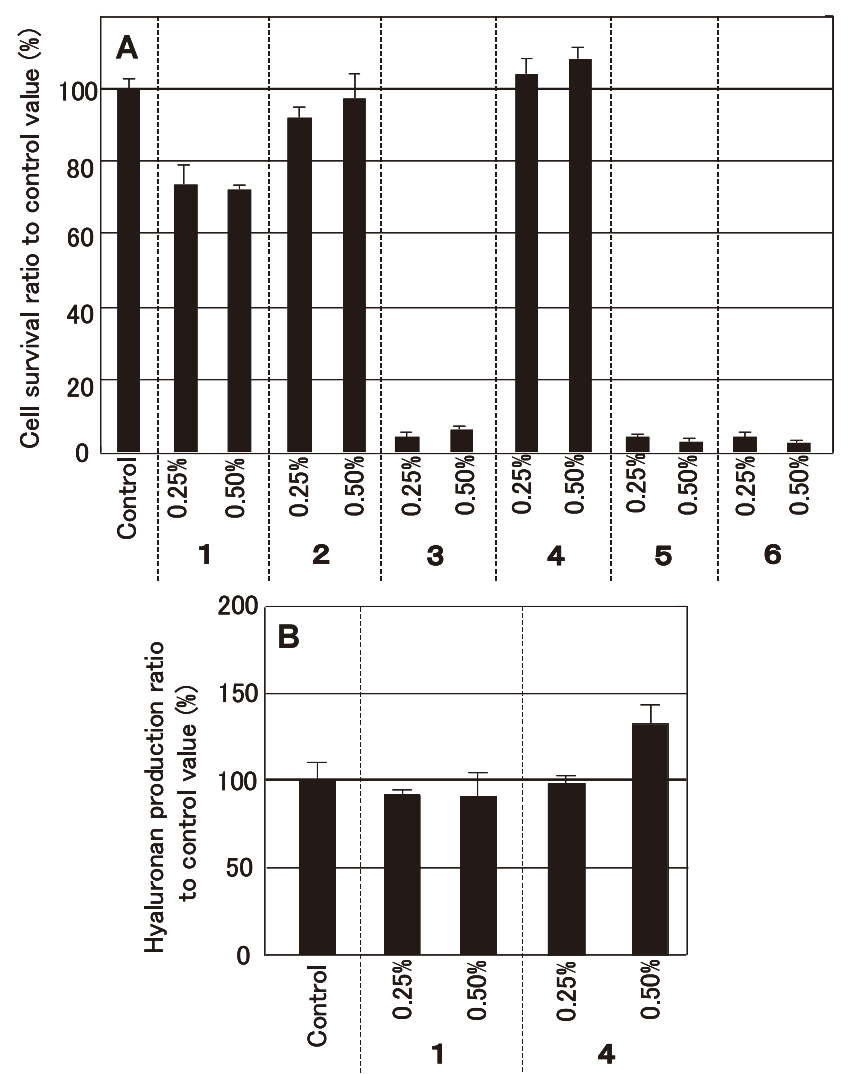

Fig.-2 Effect of addition of GlcN derivatives on survival ratio of human keratinocyte (A) and the production of hyaluronan in human keratinocyte (B).

In the control experiment, culture medium contains no GlcN derivative.

基を多く導入することにより, 細胞脂質二重膜の擋乱に よる細胞障害が起こっている可能性が考えられる。

$\mathrm{GlcNBu}$ (4)，および $\mathrm{GlcN}$ (1) の HA 産生能につい て検討を加えた。誘導体 1 と 4 以外は, 細胞毒性が強い ため, 評価系からは除いた。GlcN（1）にはHAの産生 促進作用が認められなかったが, GlcNBu（4）には $0.5 \%$ 添加により HA の産生促進作用がみられた（Fig.-2B）。 今回, 誘導体 3, 5, 6 では細胞毒性が強く, HA の産生 促進作用は見出せなかったが, 今後の課題として, 毒性 がみられない濃度での検討が必要と思われる。GlcNの $N$-ブチリル化により表皮 HA 合成促進作用が認められ たことから， $N$-疎水化は表皮 HA 合成促進剤を開発す るために有効な化学修飾である可能性が考えられ，今後 さらに検証していく必要がある。

\section{2. ヒト表皮角化細胞を用いた GICNAc 誘導体} (7〜15) の評価

GlcNAc（2）は，ヒト表皮細胞に打いて HA の生合成 を促進する作用 ${ }^{13), 14)}$ が報告されており, HA 合成酵素

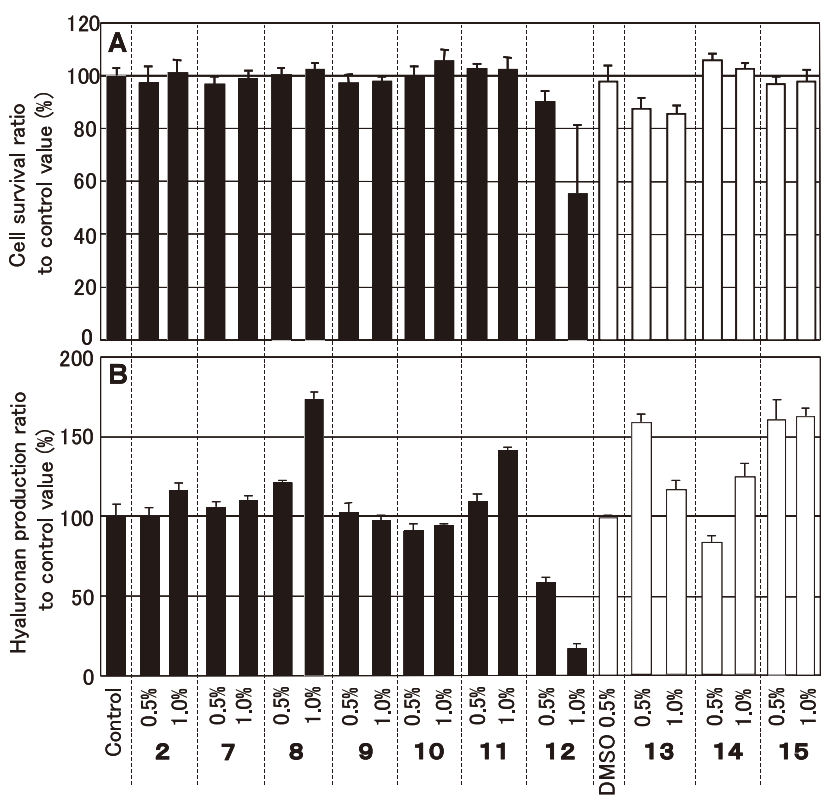

Fig.-3 Effect of addition of GlcNAc derivatives on survival ratio of human keratinocyte $(\mathrm{A})$ and the production of hyaluronan in human keratinocyte (B).

In the experiments for compound 2-12 (black bar), the compounds were dissolved in the culture medium. In the experiments for compound 13-15 (white bar), the compounds were dissolved in DMSO, because of solubility. In the control experiments, culture media contain no GlcNAc derivatives.

（HAS）遺伝子の発現には影響を及ぼさないことから， HAS には影響を及ぼさない作用メカニズムが指摘され ている。そこで, GlcNAc（2）に，種々の踈水基を導入 することにより, 細胞膜への浸透作用による HA の合成 促進作用の向上が期待される誘導体 (9 種)を合成した。 これらの誘導体のヒト表皮細胞についても細胞毒性や HA の産生促進作用を評価した。

Fig.-3A に細胞生存率を示す。誘導体 13〜15 は培地 への溶解性が低いためDMSO に溶解して実験に供し た。DMSO 自体 $(0.5 \%)$ は, 細胞毒性を示さなかった。 誘導体 12 を $1.0 \%$ 添加した場合のみ細胞生存率が $60 \%$ 未満に低下していたが，それ以外では細胞毒性はほとん どなかった。

表皮角化細胞の HA 産生に対する GlcNAc 誘導体の作 用では, 誘導体 8 㧍よび 11 に扔いて, 濃度依存的に $\mathrm{HA}$ 合成促進能が観察され，どちらも GlcNAc（2）を加 えた場合よりも高い結果となった。DMSOに溶解した 誘導体 13 では濃度依存性は認められなかったが，0.5\% 添加で高いHA 合成促進能がみられた。誘導体 15 では, 


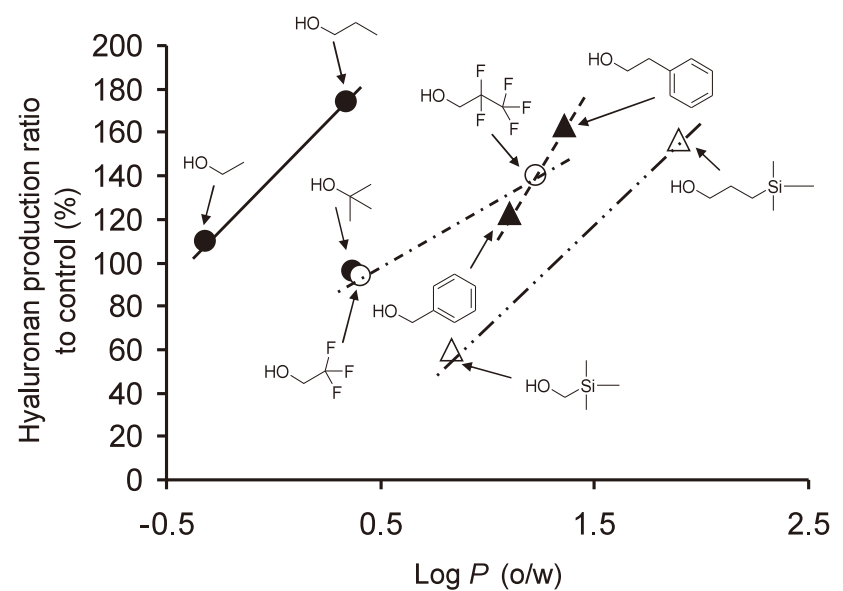

Fig. -4 Correlation of $\log P(\mathrm{o} / \mathrm{w})$ of alcohols used for derivatizations and the production ratio of hyaluronan in human keratinocyte.

$\log P(\mathrm{o} / \mathrm{w})$ data of alcohols were taken from ref. 15, except for data of hydroxymethyl trimethylsilane and 3-(trimethylsilyl)-1-propanol predicted by the software $\mathrm{ACD} / \log P \mathrm{DB}$. Values for the vertical axis were taken from the data of $1 \%$ addition of derivatives $7-11$, and 14,15 and those of $0.5 \%$ of addition of derivatives 12 and 13 in Fig. $-3 \mathrm{~B}$, because the derivatives 12 and 13 have toxicity at $1 \%$ addition.

$0.5 \%$ と $1.0 \%$ ともに高い HA 合成促進能が認められた (Fig. $-3 \mathrm{~B})$ 。

既報と同様6)，アルキルアルコールを導入した誘導体 （8）は, GlcNAc（2）と比較して，HAの産生促進作用 が優れていることが確認された。今回, 新しく検討した 含フッ素アルコールを導入 (11), 芳香族アルコールを 導入 $(14,15)$, およびケイ素アルコールを導入 (13) した誘導体は, 細胞毒性も低く, HA の産生促進作用が 高まることを見出した。今回, 誘導体 13 と 15 において は，濃度依存性を確認できなかったが，より低濃度でも HA 合成促進作用を示す可能性もあり, 今後, 詳細に検 討を重ねる予定である。

続いて, 合成した誘導体の疎水性の指標となる各アル コールの $\log P(\mathrm{o} / \mathrm{w})$ 值 ${ }^{15)}$ と $\mathrm{HA}$ 産生促進効果との相 関を調べた (Fig.-4)。アルキルアルコール, 含フッ素 アルコール, 芳香族アルコールについては, $1 \%$ 誘導体 を添加したときの Fig.-3B における相対産生量值, 含ケ イ素アルコールの場合は, $1 \%$ の添加で細胞毒性が観察 されたため, $0.5 \%$ 添加時の值を用いた。すでに報告が あるアルキルアルコールの導入は既報と同様の傾向を示 したが6)，枝分かれのあるtーブタノールでは疎水性とは 関係なく促進能が低かった。同じ鎖長で含フッ素アル
コール，含ケイ素アルコール，芳香族アルコールに分け て比較してみたところ, 同じグループ内では疎水性の大 きいほうが促進能も高かった。予想される原因として, 水溶性成分である GlcNAc の 1 位の疎水的因子が高まっ た結果, ヒト表皮細胞の細胞膜との疎水的相互作用が起 こり, 細胞膜の疎水部に対する親和性や浸透性が高まっ たためと考えられる。しかしながら，グループ間では疎 水性に応じた促進効果が観察されなかったことから，立 体効果や電子吸引性, 電子供与性などの他の要因も影響 していると推察された。今後, HA 合成促進作用を効果 的に高めるために, 導入する置換基の種類 ·位置と活性 との関係の解明など, 更なる系統的検討が必要と思われ る。

\section{4. 結論}

GlcN（1）とGlcNAc（2）に疎水基を導入した誘導体 13 種を合成し，ヒト表皮角化細胞に対する細胞毒性と $\mathrm{HA}$ 産生能に与える影響について検討した。GlcN 誘導 体において, GlcN（1）には，HA 合成促進作用はみら れなかったが，N位をブチリル化した GlcNBu（4）は細 胞毒性もなく, HA 合成促進作用がみられた。他の誘導 体 $(3,5,6)$ は強い毒性を示した。GlcNAc 誘導体では, より疎水性の高いフッ素やケイ素, 芳香核を含むアル コールを 1 位に結合させた新規 GlcNAc 誘導体 (11, 13,15）は, 細胞毒性もなく,HA 合成促進作用を示した。 GlcNAc 誘導体の HA 産生促進能と導入側鎖の構造との 関係から，HA 促進作用を高めるには疎水性に加えて， 他の要因も産生促進に影響していることが示唆された。 $N$ 位をブチリル化した $\mathrm{GlcN}$ 誘導体や 1 位に分岐構造を 有さない疎水部を結合させた GlcNAc 誘導体は, 皮膚老 化対策や皮膚保湿機能の改善を目的とした表皮 HA 合成 促進剂として有望な成分であると考えられた。

\section{引用文献}

1）阿武喜美子, 瀬野信子, 糖化学の基礎, 講談社サイエ ンティフィック，東京，1984, p. 79-81

2) Y. Tamai, K. Miyatake, Y. Okamoto, Y. Takamori, H. Sakamoto, S. Minami, Carbohydr. Polym., 48, 369-378 (2002)

3）華 見, 宮澤敬治, 坂本廣司, 長岡 功, キチン・キ トサン研究，13, 239-244（2007）

4) A. Breborowicz, M. Kuzlan-Pawlaczyk, K. WieczorowskaTobis, J. Wisniewska, P. Tam, I. French, G. Wu, Adv. Peritoneal Dialysis, 14, 31-35 (1998)

5) A. R. Shikhman, K. Kuhn, N. Alaaeddine, M. Lotz, J. Immunol., 166, 5155-5160 (2001) 
6）佐用哲也, 福永恭子, 杉山義宣, 井上伸太郎, 日本薬 学会第 127 回年会要旨集 $(2), 38$ (2007)

7) M. W. Poustie, J. Carran, K. McEleney, S. J. Dixon, T. P. Anastassiades, S. M. Bernier, J. Pharmacol. Exp. Ther., 311, 610-616 (2004)

8) M. Bergmann, L. Zervas, Ber., 64B, 975-980 (1931)

9) Y. Inouye, K. Onodera, S. Kitaoka, S. Hirano, J. Am. Chem. Soc., 78, 4722-4724 (1956)

10) S. Nishimura, T. Furuike, K. Matsuoka, Methods Enzymol., 242, 235-246 (1994)
11）加賀出穂, 五十嵐庸, 野口貴子, 黒住誠司, 高森吉守, 坂本廣司, 有福一郎, 宮澤敬治, 華 見, 長岡 功, キチン・キトサン研究，14，120-121（2008）

12) R. Gay, M. Swiderex, D. Nelson, A. Ernesti, Toxicol. In Vitro, 6, 303-315 (1992)

13) T. Sayo, S. Sakai, S. Inoue, Skin Pharmacol. Physiol., 17, 77-83 (2004)

14）酒井進吾,佐用哲也, ファインケミカル, 30, 5-11(2001)

15) A. Leo, C. Hansch, D. Elkins, Chem. Rev., 71, 525-616 (1971)

\title{
Effect of Hydrophobic D-Glucosamine Analogues on Production of Hyaluronan in Human Keratinocyte and Structural Activity*
}

\author{
Shinichi Yoshida ${ }^{* *}$, Shinichi Kimura ${ }^{* *}$, Keiko Kitamura ${ }^{* *}$, Haruyoshi Seino ${ }^{* * *}$ \\ Tottori Institute of Industrial Technology**, \\ Central Research Laboratory, Pias Corporation ${ }^{* * *}$
}

D-Glucosamine (GlcN) (1), $N$-acetyl-D-glucosamine (GlcNAc) (2) , and alkyl $N$-acetyl- $\beta$ D-glucosaminide are known to stimulate the production of hyaluronan production in human keratinocyte. Novel hydrophobic derivatives 1 and 2 were synthesized, and the effect of these derivatives on the production of hyaluronan in human keratinocyte was investigated. While GlcN had no effect on the production of hyaluronan in the keratinocyte, $N$-butyryl- $\beta$-D-glucosamine (4) stimulated production. To investigate the mechanism of this stimulation, four subgroups of derivatives of $N$-acetyl- $\beta$-D-glucosaminide were synthesized that contained alkyl alcohols, fluoro alcohols, silyl alcohols, and aromatic alcohols, respectively (10-15). Correlation of $\log P$ $(\mathrm{o} / \mathrm{w})$ of the alcohol moieties and hyaluronan production was investigated. The production ratio of hyaluronan to the control experiments increased with an increase of $\log P$ values within each subgroup. However, no correlation was observed between these four subgroups, suggesting that other factors are related to the stimulation of hyaluronan production.

Key words : D-glucosamine, $N$-acetyl-D-glucosamine, human keratinocyte, hyaluronan, $1,3,4,6$-tetra- $O$-acetyl- $\beta$-D-glucosamine, $N$-butyryl- $\beta$-D-glucosamine, alkyl $N$-acetyl- $\beta$-Dglucosaminide, 2,2,3,3,3-pentafluoro-1-propyl $N$-acetyl- $\beta$-D-glucosaminide, phenetyl $N$-acetyl$\beta$-D-glucosaminide, (trimethylsilyl) methyl $N$-acetyl- $\beta$-D-glucosaminide, $\log P(\mathrm{o} / \mathrm{w})$ 